\title{
Accuracy of perception of severity of asthma: patients treated in general practice
}

\author{
A H Kendrick, C M B Higgs, M J Whitfield, G Laszlo
}

Abstract

Objective-To determine the frequency of poor perception of severity of asthma in general practice.

Design-Asthmatic patients recorded their perceived severity of asthma, with a visual analogue score, and a coded measurement of their peak expiratory flow up to four times daily for 14 consecutive days.

Settings-11 general practices in and around Bristol.

Subjects-255 asthmatic patients (139 men and 116 women) aged 17-76 who were recruited by random selection from the general practices' disease registers or when they requested prescriptions for inhaled bronchodilators.

Main outcome measures-Correlation between visual analogue scores and peak expiratory flow (as a percentage of predicted peak flow).

Results $-152(60 \%)$ of the patients showed no significant correlation between visual analogue asthma scores and simultaneous peak flow measurements $(p>0.05)$ and were termed poor discriminators. The distribution of good and poor discriminators within each general practice was similar $\left(\chi^{2}=6 \cdot 11, d f=10\right)$. The two groups were not characterised by differences in the maximum, minimum, or standard deviation of peak expiratory flow or visual analogue score; in age; or in the proportion of men and women in each group.

Conclusion-In general practice a high proportion of asthmatic patients do not reliably detect changes in their lung function. This reinforces the need for careful objective assessment of lung function in the management of asthma.

\section{Introduction}

Treatment for asthma, whether by a physician or a Respiratory Department, Bristol Royal Infirmary, Bristol BS2 8HW

A H Kendrick, research scientist

C M B Higgs, honorary senior registrar

G Laszlo, consultant

physician

General Practice Unit, Department of Epidemiology and Public Health, University of Bristol, Bristol M J Whitfield, consultant senior lecturer

Correspondence to:

Dr Kendrick. the potential problem of perception of asthma in general practice or in the community. The purpose of this study was to investigate the ability of asthmatic patients treated by general practitioners to assess changes in their peak expiratory flow under normal daily conditions.

\section{Subjects and methods}

During 1987-90 we recruited 255 patients from 11 general practices in or near to Bristol that participated in the study. Four practices were from rural locations, and the rest were from central Bristol. They were selected on the basis of locality in an attempt to obtain patients from as wide a range of social classes and environments as possible. The patients were randomly selected from asthmatic patients listed on the disease registers of the general practices or were recruited when they requested prescriptions for inhaled bronchodilators. None was known to the single interviewer (AHK). Each patient's informed written consent was obtained, as was the local ethical committee's approval.

During a structured interview lasting one hour the patients were instructed in the use of a coded peak flow meter and a visual analogue scale and were allowed several practice attempts. The coded peak flow meter was a hand held electronic rotating vane turbine spirometer (Servonetics) with an output producing a numeric code. ${ }^{6}$ This code prevented the patients from knowing their peak flow and therefore removed any influence that this may have had on subjective self assessment of asthma. ${ }^{7}$ The visual analogue scale was a $100 \mathrm{~mm}$ line running from "No asthma" at the left end to "Most severe asthma" at the right, which referred to the worst ever sensation of asthma a patient could recall experiencing. ${ }^{7}$ The patients were asked to place a vertical mark on the line such that its position relative to the two extremes indicated the severity of their asthma.

The patients were then given a peak flow meter and a diary card which allowed the patients to record three coded peak expiratory flow readings up to four times daily-morning, noon, early evening, and bedtime. On each occasion the patients also assessed their asthma with the visual analogue scale to answer the question: "How is your asthma?" The patients were told that this related to the severity of their asthma at the time of the reading. The patients were asked to make recordings for 14 consecutive days, their medication remaining unchanged for that period.

The subjective assessments of severity of asthma were recorded as the length $(\mathrm{mm})$ from the left end of the analogue scale to the position of the vertical mark. All the coded peak expiratory flow values were decoded, and the highest of the three values for each time was used for subsequent analysis. The percentage variation in peak expiratory flow over the 14 days was calculated for each patient as (maximum value-minimum value)/ maximum value. For each patient, plots of visual analogue score against peak expiratory flow (expressed as a percentage of the predicted peak flow) and its natural logarithm were obtained. Predicted values of 


\section{(a) Good}

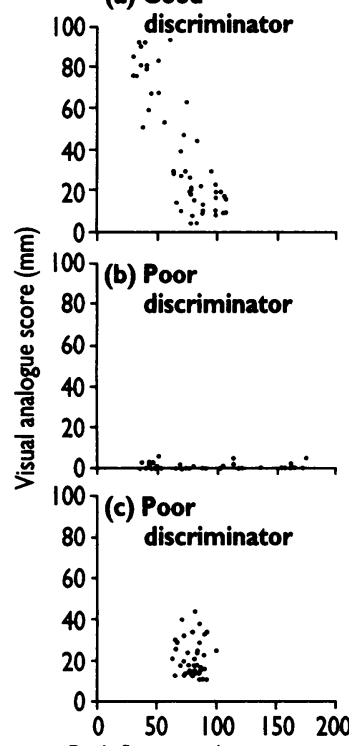

Peak flow rate (as percentage of predicted peak flow)

Individual recordings of visual analogue scores and

simultaneous peak expiratory flow (as a percentage predicted peak flow) by (a) one good discriminator and $(b, c)$ two poor discriminators

TABLE I-Distribution of 255 asthmatic patients in 11 general practices by their ability to accurately perceive severity of their asthma

\begin{tabular}{|c|c|c|}
\hline \multirow[b]{2}{*}{$\begin{array}{l}\text { Practice } \\
\text { No }\end{array}$} & \multicolumn{2}{|c|}{ No $(\%)$ of patients } \\
\hline & $\begin{array}{c}\text { Good } \\
\text { discrimi- } \\
\text { nators }\end{array}$ & $\begin{array}{c}\text { Poor } \\
\text { discrimi- } \\
\text { nators }\end{array}$ \\
\hline $1(\mathrm{n}=20)$ & $11(55)$ & $9(45)$ \\
\hline $2(\mathrm{n}=23)^{\star}$ & $10(43)$ & $13(57)$ \\
\hline $3(n=41)$ & $16(39)$ & $25(61)$ \\
\hline $4(n=39)$ & $15(38)$ & $24(62)$ \\
\hline $5(\mathrm{n}-30)$ & $12(40)$ & $18(60)$ \\
\hline $6(n=7)^{\star}$ & $2(29)$ & $5(71)$ \\
\hline $7(\mathrm{n}=9)^{\star}$ & $4(44)$ & $5(56)$ \\
\hline $8(\mathrm{n}=49)^{\star}$ & $18(37)$ & $31(63)$ \\
\hline $9(\mathrm{n}=19)$ & $6(32)$ & $13(68)$ \\
\hline $10(n=4)$ & $1(25)$ & $3(75)$ \\
\hline $11(\mathrm{n}=14)$ & $8(57)$ & $6(43)$ \\
\hline $\begin{array}{l}\text { Total } \\
\qquad(n=255)\end{array}$ & $103(40)$ & $152(60)$ \\
\hline
\end{tabular}

*Rural practices: the others were urban.

TABLE II-Characteristics of 255 asthmatic patients by their ability to accurately perceive severity of their asthma. Values are means (standard deviations) unless stated otherwise

\begin{tabular}{|c|c|c|c|}
\hline & $\begin{array}{c}\text { Good } \\
\text { discriminators } \\
(n=103)\end{array}$ & $\begin{array}{c}\text { Poor } \\
\text { discriminators } \\
(n=152)\end{array}$ & $\mathrm{p}$ Value \\
\hline $\begin{array}{l}\text { No and sex of patients } \\
\text { Age (years) } \\
\text { No of recordings made } \\
\text { Peak expiratory flow }(\%)^{\star} \text { : }\end{array}$ & $\begin{array}{l}60 \mathrm{M} 43 \mathrm{~F} \\
42 \cdot 2(14 \cdot 2) \\
44 \cdot 3(8 \cdot 2)\end{array}$ & $\begin{array}{l}79 \mathrm{M} \quad 73 \mathrm{~F} \\
44 \cdot 3(14 \cdot 4) \\
44 \cdot 9(7 \cdot 9)\end{array}$ & $\begin{array}{c}>0.30\left(\chi^{2}=0.98\right) \\
0.25 \\
0.52\end{array}$ \\
\hline $\begin{array}{l}\text { Minimum } \\
\text { Maximum } \\
\text { Median (range) standard deviation }\end{array}$ & $\begin{array}{l}40 \cdot 4(23 \cdot 1) \\
103 \cdot 5(28 \cdot 8) \\
13 \cdot 3(5 \cdot 2-71 \cdot 7)\end{array}$ & $\begin{array}{l}40 \cdot 5(21 \cdot 5) \\
100(34 \cdot 4) \\
12 \cdot 5(2 \cdot 8-67)\end{array}$ & $\begin{array}{l}0 \cdot 78 \\
0 \cdot 40 \\
0 \cdot 18\end{array}$ \\
\hline $\begin{array}{l}\text { Visual analogue score (mm): } \\
\text { Minimum } \\
\text { Maximum } \\
\text { Median (range) standard deviation } \\
\text { Variation in peak expiratory flow }(\%)^{\star}\end{array}$ & $\begin{array}{l}4.0(9 \cdot 4) \\
34 \cdot 9(25 \cdot 3) \\
5 \cdot 9(0 \cdot 8-29) \\
62 \cdot 3(15 \cdot 2)\end{array}$ & $\begin{array}{l}2 \cdot 7(6 \cdot 2) \\
34 \cdot 4(27 \cdot 8) \\
6 \cdot 1(0-29 \cdot 8) \\
60 \cdot 3(15 \cdot 6)\end{array}$ & $\begin{array}{l}0.53 \\
0.64 \\
0.54 \\
0.23\end{array}$ \\
\hline
\end{tabular}

*Peak expiratory flow expressed as percentage of predicted peak flow. admitted to having asthma most of the time, as shown by visual analogue scores above zero, but nevertheless showed a wide scatter of scores at any given peak expiratory flow. Others gave only low scores to describe even low values of peak flow; such patients tend also to deny other forms of stress. ${ }^{10}$

We used a coded peak flow meter because it has been shown that a subject's knowledge of recent trends in peak expiratory flow influences that person's self assessment of asthma. ${ }^{7}$ Only 10 patients were using their own flow meters at the time of interview, and these were exchanged for coded meters during the study. To allow comparisons between individuals, we plotted peak flow as a percentage of the predicted peak flow. This was expressed as a logarithm to magnify changes at the lower end of the range. This made little difference for most of the subjects, but for many the correlation coefficients were higher.

Most studies to compare asthmatic patients' subjective assessment of symptoms with the degree of airflow obstruction have been laboratory based and have tended to use highly selected groups of subjects. McFadden et al reported that most of their subjects, while recovering from an acute asthma attack, became symptom free when their airways conductance was still below $50 \%$ of normal. ${ }^{11}$ Rubinfeld and Pain found that $15 \%$ of their asthmatic subjects could not detect changes of airway calibre induced by pharmacological bronchoconstrictors, ${ }^{12}$ and similar results were found with a group of patients recruited from a hospital clinic who were studied with techniques used on this study. ${ }^{13}$ A study of dyspnoea and airflow obstruction showed that 22 of 35 asthmatic subjects showed a poor correlation between their estimation of the magnitude of their dyspnoea and their peak flow rate, ${ }^{14}$ but a correlation coefficient of 0.7 was used to distinguish good and poor perceivers, which is probably too stringent. In a study essentially similar to ours 31 adolescents made 36 observations during 12 days in a summer camp and were classified on the basis of the correlation coefficient between the visual analogue scores and peak expiratory flow: a coefficient of -0.6 and better was taken as high accuracy $(p<0.001,22 \%$ of subjects), of -0.3 to -0.59 as moderate accuracy ( $p<0.05,55 \%$ of subjects), and of 0 to -0.29 as low accuracy ( $p>0.05,23 \%$ of subjects). ${ }^{15}$ We chose a $\mathrm{p}$ value of $<0.05$ to allow for the differing number of observations, but selecting a value of $<0.1$ would not have altered our conclusions.

A number of confounding factors might have contributed to our results. Some of the patients might have failed to grasp the idea of the visual analogue score. With training, most patients can produce satisfactory readings of peak flow with a coded meter ( $P$ S Burge, personal communication): in the most pessimistic estimate $30 \%$ of readings might have been inaccurate. ${ }^{16}{ }^{17}$ If $25 \%$ of the results were inaccurate for these reasons the estimated number of poor discriminators would still be as high as $45 \%$ of the total. In some cases other lung function variables such as lung volume might have changed during the study. Allowing for some sources of error, the most likely explanation for our results is that many patients, when asked about the severity of their asthma, gave an answer which reflects recent trends in respiratory sensation. ${ }^{7}$ They do not regard the sensation associated with low readings of peak flow as severe constriction if they expect to improve soon.

The reasons for the difference between our results and those of previous studies could include differences in the control of asthma, in the education of the patients, and in the characteristics of the general practices as well as method of recruitment. While it was clear to the interviewer that a higher proportion of the patients from some practices than from others 


\section{Clinical implications}

- Treatment for asthma is usually guided by patients' perceptions of their symptoms

- If patients cannot accurately judge their symptoms' severity, however, they may not be adequately treated

- In this study of asthmatic patients treated in general practice more than half discriminated poorly between high and low values of peak flow

- Poor discrimination was not linked to sex, age, or particular practices

- Management of asthma should be based on objective measurements of peak flow as well as self assessment of symptoms

understood their condition poorly this did not reflect the proportion of poor discriminators in each practice. At the time of the study only $10 \%$ of the patients used peak flow meters regularly. Many of the patients had used meters previously and some still had them, but they regarded their asthma as insufficiently serious to warrant the continued use of meters.

The patients who were poor discriminators were not characterised by having low maximum values of peak flow nor did they record the lowest peak flow readings, and the proportions of men and women who were good and poor discriminators were similar, as has been found in other studies. ${ }^{1819}$ It is not known whether poor discriminators have a worse prognosis than those able to assess changes in their asthma. Poor perception of asthma during severe attacks may account for a proportion of those deaths when patients and doctors have not appreciated the severity of the condition..$^{1.320}$ Our results support the assertion that careful attention should be paid to the monitoring of lung function at home by asthmatic patients whether they are symptomatic or not.

We thank the general practitioners and their staff for giving us access to their patients and the patients who cooperated in this study. This study was supported by the National Asthma Campaign.

1 Ormerod LP, Stableforth DE. Asthma mortality in Birmingham 1975-7: 53 deaths. $B M \mathcal{F} 1980 ; 280: 687-90$

Johnson AJ, Nunn AJ, Somner AR, Stableforth DE, Stewart CJ. Circumstances of death from asthma. $B M{ }^{\prime} 1984 ; 288: 1870-2$.

3 Sears LR, Rea HH, Rothwell RPG, O'Donnell TV, Holst PE, Gillies AJD, et al. Asthma mortality: comparison between New Zealand and England. BMf 1986;293:1342-5.

4 Bates DV. Respiratory function in asthma. Clin Sci 1952;11:203-7.

4 Bates DV. Respiratory function in asthma. Clin Sci 1952;11:203-7.
5 Rubinfeld AR, Pain MCF. Perception of asthma. Lancet 1976;:882-4.

5 Rubinfeld AR, Pain MCF. Perception of asthma. Lancet 1976;i:882-4.
6 Richardson RB, Higgs CMB, Lea DA, Lewis GTR, Laszlo G. An electronic peak flow meter with optional coded display. Clin Phys Physiol Meas 1984;5:201-6.

7 Higgs CMB, Richardson RB, Lea DA, Lewis GTR, Laszlo G. Influence of knowledge of peak flow on self assessment of asthma: studies with a coded peak flow meter. Thorax 1986;41:671-5.

8 Quanjer PH. Standardized lung function testing. Bull Eur Physiopathol Respir 1983;19(suppl 5):7-10.

9 Siegel S, Castallan NJ. Nonparametric statistics for the behavioral sciences. 2nd ed. New York: McGraw-Hill, 1988.

10 Steiner H, Higgs CMB, Fritz GK, Laszlo G, Harvey JE. Defense style and the perception of asthma. Psychosom Med 1987;49:35-44.

11 McFadden ER, Kiser R, deGroot WJ. Acute bronchial asthma: relations between clinical and physiologic manifestations. $N$ Engl 7 Med 1973;288: 221-5.

12 Rubinfeld AR, Pain MCF. Relationship between bronchial reactivity, airway caliber, and the severity of asthma. Am Rev Respir Dis 1977;115:381-7.

13 Higgs CMB. Studies on the perception of asthma [dissertation]. Cambridge: University of Cambridge, 1987.

14 Peiffer C, Marsac J, Lockhart A. Chronobiological study of the relationship between dyspnoea and airway obstruction in symptomatic asthmatic subjects. Clin Sci 1989;77:237-44.

15 Fritz GK, Klein RB, Overholser JC. Accuracy of symptom perception in childhood asthma. 7 Dev Behav Padiatr 1990;11:69-72.

16 Hetzel MR, Williams IP, Shakespeare RM. Can patients keep their own peakflow records reliably? Lancet 1979;i:597-9.

17 Clark NM, Evans D, Mellins RB. Patients use of peak flow monitoring. Am Rev Respir Dis 1992;145:722-5.

18 Burdon JGW, Juniper EF, Killian KJ, Hargreave FE, Campbell EJM. The perception of breathlessness in asthma. Am Rev Respir Dis 1982;126:825-8.

19 Rubinfeld AR, Pain MCF. Conscious perception of bronchospasm as a protective phenomenon in asthma. Chest 1977;72:154-8.

20 Barnes PJ. Poorly perceived asthma. Thorax 1992;47:408-9.

(Accepted 3 fune 1993)

\section{A PATIENT WHO CHANGED MY PRACTICE}

\section{Measuring blood pressure}

Two types of patients cause the heart to sink in a hypertension clinic. One is the unfortunate individual whose blood pressure is never properly controlled. Visits become a triumph of hope over experience and are usually terminated when the accusation of non-compliance produces what management textbooks often refer to as a confrontational situation. There is also the patient whose blood pressure is measured by the general practitioner and referred with hypertension but who does not obviously appear to have it. It may be necessary to carry out 24 hour blood pressure monitoring to confirm the point. In some cases too small a cuff has been used on an obese arm. In others I suspect that the reason is less flattering to those of us who run hypertension clinics. The prolonged waiting time followed by a further period of rest on a couch may achieve a more basal blood pressure than immediate measurement on arrival at a doctor's surgery. In this respect the patient's charter may significantly affect the level of blood pressure control in our clinic.

Neither of these reasons was relevant to the patient who changed my clinical practice. A middle aged gentleman had been attending our clinic for four to five months with an initial diagnosis of mild hypertension. His blood pressure had been well controlled with pressures consistently below $140 / 90$ on each attendance. During this period, however, he also had his blood pressure measured by his general practitioner with values of about $170 / 110$ on two or three occasions. Twenty four hour ambulatory blood pressure monitoring was not available at the time and the last doctor who saw him in our clinic concluded that the general practitioner's readings were the result of quite a major alerting response. This was puzzling as the patient showed no signs of anxiety or tension. The denouement occurred when the patient arrived with a further note from his general practitioner. The practice had instituted blood pressure measurements by a practice nurse who had pointed out that the patient's blood pressure was substantially lower in the right arm compared with the left. This was indeed the case and further examination showed a subclavian bruit indicating a subclavian stenosis on the right arm.

The British Hypertension Society's guidelines for blood pressure measurements state clearly that blood pressure should be measured in both arms in all patients at initial assessment, ${ }^{1}$ Unfortunately, this does not always happen and few of us check whether it has been carried out when we see a patient for a follow up visit. This patient taught me an important lesson and also underlined the fact that normotensive blood pressure levels can occasionally be just as spurious as raised blood pressure levels. $\rightarrow$ J SWALES is professor of medicine in Leicester

1 Petrie JC, O'Brien ET, Littler WA, de Swiet M. British Hypertension Society recommendations in blood pressure measurement. $B M F$ 1986; 293:611-5.

We welcome contributions to fillers: $A$ patient who changed my practice; $A$ paper that changed my practice; $A$ memorable patient; The message I would most like to leave behind, or similar topics. 